www.jmscr.igmpublication.org

Impact Factor 5.84

Index Copernicus Value: 71.58

ISSN (e)-2347-176x ISSN (p) 2455-0450

crossref DOI: _https://dx.doi.org/10.18535/jmscr/v6i1.140

Journal Of Medical Science And Clinical Research

\title{
Fetomaternal Outcome in Placenta Previa with Unscarred Uterus (One Year Prospective Study)
}

\author{
Authors \\ Dr Khushpreet Kaur, Dr Rama Garg, Dr Arvinder Kaur, Dr Ruchi Jindal \\ Corresponding Author \\ Dr Rama Garg
}

\section{Abstract}

Placenta Previa with unscarred uterus is the major cause of antepartum haemorrhage that causes serious morbidity and mortality to both fetus and mother.

Objective: To study the maternal outcome in placenta previa with unscarred uterus. To study the fetal outcome in Placenta previa with unscarred uterus.

Material and Methods: This was the one year prospective study conducted in Govt. Medical College, Patiala in cases of placenta previa with unscarred uterus. During the study period out of 3784 deliveries 86 cases of placenta previa were reported. There were 38 cases of placenta previa with unscarred uterus.

Results: Present study confirmed that incidence of placenta previa in unscarred cases is significantly high. The no. of unbooked cases was high. There was one maternal death. Our study showed favourable fetal outcome.

Conclusion: The frequency of placenta previa in unscarred uterus is slightly higher in our study than other studies and this problem may be estimated for further planning and management of placenta previa.

Keywords: Placenta previa, maternal outcome, fetal outcome.

\section{Introduction}

Placenta previa refers to placenta that is situated wholly or partially in the lower uterine segment. 1It is associated with significant maternal and fetal morbidity and mortality because of unanticipated blood loss and is of the most acute life threatening emergency in obstetrics. Frequency varies with parity; for nulliparous incidence is $0.2 \%$ whereas in grand multiparous it may be as high as $5 \% .2$ Other risk factors include maternal age greater than or equal to 35 years, non white ethinicity, multiple pregnancy, smoking and previous abortion. ${ }^{3}$

Placenta previa with unscarred uterus complicates $0.3 \%-0.5 \%$ of all pregnancies and is a major cause of third trimester haemorrhage.. Significant maternal morbidity in the form of increased incidence of caesarean delivery, increased blood loss and peripartum hysterectomy have been noted in cases of placenta previa and can lead to prolonged hospitalisation in these women.

Premature deliveries occur which lead to higher admission to neonatal intensive care unit and stillbirths.

The traditional classification of placenta previa describes the degree to which the placenta encroaches upon the cervix in labor and is divided into low lying, marginal, partial or complete placenta previa. ${ }^{4}$ Recent revised classification of placenta previa consist of two variations: 
True placenta previa in which internal cervical os is covered by placental tissue and low lying placenta in which placenta lies within $2 \mathrm{~cm}$ of cervical os but does not cover it. ${ }^{5}$

Along with history, clinical examination and ultrasound, MRI has been used in patients with placenta previa, esp. to diagnose adherent placenta. It has been speculated that uterine scarring due to trauma, infection or surgery lead to endomyometrial junction abnormality causing abnormal vascularisation which reduces the differential growth of the lower segment. This prevents placental migration as pregnancy advances.

The aim of this study was to examine the risk factors and fetomaternal outcome in previously unscarred uterus with placenta previa.

Haemorrhage is leading cause of death worldwide. Placenta previa is a major cause of haemorrhage worldwide and frequency of this condition is on rise. ${ }^{6}$ So we need to identify and target women at high risk of placenta previa.

Frequency of placenta previa is increasing in primigravida and multigravida with unscarred uterus. So this study was planned to find out the frequency of placenta previa in unscarred uterus so that the management of the problem may be estimated for further planning and management.

\section{Methods}

This prospective study was conducted in the department of OBGY at Govt. Medical College Patiala. Cases of placenta previa in unscarred uterus from Feb 2016 to Jan 2017 were studied. Inclusion criteria was all Women over 28 weeks of gestation with placenta previa in unscarred uterus, Placental localisation was achieved by transabdominal ultrasounds in these patients.

Risk factors in terms of maternal age, parity, gestational age, were studied.

\section{Data tabulation}

Total number of deliveries $=3784$

Total no. of patients with unscarred uterus $=2259$

Total number of placenta previa $=86$
Overall incidence of placenta previa $=2.27 \%$

Total no. of placenta previa in unscarred uterus $=38$

Incidence in unscarred uteri $=1.68 \%$

Table 1: Maternal characteristics

\begin{tabular}{|l|c|c|}
\hline Age(yrs) & No. & \% \\
\hline$<25$ & 23 & 60.53 \\
\hline $25-30$ & 10 & 26.32 \\
\hline $31-35$ & 4 & 10.53 \\
\hline$>36$ & 1 & 2.62 \\
\hline Parity & & \\
\hline 0 & 11 & 28.96 \\
\hline 1 & 8 & 21.05 \\
\hline 2 & 10 & 26.31 \\
\hline$>3$ & 9 & 23.68 \\
\hline Gestational age(weeks) & & \\
\hline$<37$ & 20 & 52.63 \\
\hline$>37$ & 18 & 47.37 \\
\hline
\end{tabular}

$60.53 \%$ of women in the study were less than 25 years of age while $2.62 \%$ of women with unscarred uteri were over 36 years of age. More than $50 \%$ of women were multiparous. .Significant no. of women delivered before 37 weeks of gestation (52.63\%).High number of patients were unbooked $(66.6 \%)$.

Table 2: Type and grading of placenta previa

\begin{tabular}{|l|c|c|}
\hline Grading & No. & \% \\
\hline Major & 31 & 81.58 \\
\hline Minor & 7 & 18.12 \\
\hline Type & & \\
\hline Anterior & 13 & 34.21 \\
\hline Posterior & 25 & 65.79 \\
\hline Invasive placenta & & \\
\hline Accreta & 0 & 0 \\
\hline Percreta & 0 & 0 \\
\hline
\end{tabular}

$81.58 \%$ had major degree placenta previa. Majority of the patients had posterior placenta $(65.79 \%)$.There was no case of adherent placenta.

Table 3: Complication

\begin{tabular}{|l|c|c|}
\hline Fetal malpresentation & 8 & $21.05 \%$ \\
\hline PPH & 10 & $26.31 \%$ \\
\hline Adherent placenta & 0 & 0 \\
\hline Haemorrhagic shock & 1 & $2.63 \%$ \\
\hline Maternal mortality & 1 & $2.63 \%$ \\
\hline
\end{tabular}

Table 3: Shows the complications. There were 10 Cases of PPH out of which $8(21.05 \%)$ were 
Controlled by uterotonics alone. Uterine artery ligation done in $2.63 \%$. Blood Transfusion was given in $68.41 \%$ of cases. Caesarean hysterectomy was done in only one case due to haemorrhagic shock. There was one maternal death.

Table 4: Management of Complications

\begin{tabular}{|l|c|c|}
\hline Blood transfusion & 26 & $68.41 \%$ \\
\hline Uterotonics & 8 & $21.05 \%$ \\
\hline Placental bed suturing & 2 & $5.26 \%$ \\
\hline Uterine packing & 1 & $2.63 \%$ \\
\hline Ballon tamponade & 2 & $5.26 \%$ \\
\hline Uterine artery ligation & 1 & $2.63 \%$ \\
\hline Internal iliac ligation & 0 & $0 \%$ \\
\hline Caesarean hysterectomy & 1 & $2.63 \%$ \\
\hline
\end{tabular}

Table 5: Distribution of fetal outcome

\begin{tabular}{|l|l|l|}
\hline Fetal outcome & No. & \% \\
\hline Alive & 36 & 94.74 \\
\hline Still birth & 2 & 5.26 \\
\hline Neonatal deaths & 3 & 8.82 \\
\hline Total & 38 & 100 \\
\hline
\end{tabular}

Fetal outcome was favourable $(94.74 \%)$

Table No.6 Distribution according to mode of delivery

\begin{tabular}{|l|c|c|}
\hline Mode of delivery & No. & \% \\
\hline Vaginal & 3 & $7.89 \%$ \\
\hline Emergency cesarean & 19 & $50 \%$ \\
\hline Elective cesarean & 16 & $42.10 \%$ \\
\hline Total & $\mathbf{3 8}$ & $\mathbf{1 0 0}$ \\
\hline
\end{tabular}

Vaginal delivery occurred in $7.89 \%$ subjects and $58.33 \%$ needed emergency Caesarean sections.

Table 7-Relative Incidence

\begin{tabular}{|l|c|c|}
\hline $\begin{array}{l}\text { Overall incidence of } \\
\text { placenta previa }\end{array}$ & $\begin{array}{c}\text { Incidence in } \\
\text { scarred uteri }\end{array}$ & $\begin{array}{c}\text { incidence in } \\
\text { unscarred cases }\end{array}$ \\
\hline $2.27 \%$ & $3.14 \%$ & $1.68 \%$ \\
\hline
\end{tabular}

\section{Discussion}

The overall incidence of placenta previa in our study was $2.27 \%$ which is higher than the study by Gayatri et al $(0.62 \%)^{8}$, and Ahmed et al $(1.3 \%)^{7}$. The incidence of placenta previa in women with unscarred uterus in our study group was $1.68 \%$ which is similar to study by Saima gul bashir $1.19 \%^{9}$

In our study maximum number of women were $<25$ years of age $(60.23 \%)$ Which is consistent with Gayatri et al who reported the incidence of placenta previa as $68 \%$ in 20-25 years .Reddy et al reported $73 \%$ incidence in 20-29 years age group $^{10}$ which is comparable to $71.6 \%$ in our study. According to the study by hung et al $71.3 \%$ were in age group of 20-35 years which is lower than our results i.e $84.1 \%$.

Our study shows increasing parity increases the risk of placenta previa. The results are consistent with Reddy et al in which $69 \%$ were multiparous. $52.63 \%$ women had preterm births. Similar results were found by Gayatri et al where $58 \%$ of women had premature births. ${ }^{3}$ There were 2 still births $(5.26 \%)$ in our study comparable to $9 \%$ in the study by Gayatri et al and $13.2 \%$ by Ahmed et al. ${ }^{2}$ There was one maternal deaths in this study similar to study of Gayatri et al. ${ }^{2}$

\section{Conclusion}

The incidence of placenta previa with unscarred uterus is on rise. The emphasis should be on institutional delivery in a tertiary care centre with multidisciplinary care i.e. involvement of senior obstetrician, anaesthetist, neonatologist, sonologist and haematologist.

The family planning services should be further improved to attain a decline in the number of women of high parity. The morbidity associated with placenta previa can be reduced by detecting the condition in the antenatal period by ultrasound, before it becomes symptomatic. Early diagnosis by ultrasound and planned delivery should be the goal.

\section{References}

1. Rahim R, Shafqat T, Fayyaz S. An analysis of association of scarred uterus with placenta previa and morbid adherence of placenta. J Med Sci 2009;17:60-3.

2. Naz S, Parveen R, Bhatti A. Major placenta previa-a true obstetric emergency. Med Chan 2009; 15: 64-7.

3. Lavery JP. Placenta previa. Clin Obstet Gynaecol 1990; 33: 414-6. 
4. Oppenheimer L; Society of Obstetricians and Gynaecologists of Canada. Diagnosis and management of placenta previa. $\mathbf{J}$ Obstet Gynaecol Can 2007;29(3):261-73.

5. Steven G.Gabbe,Jennifer $\mathrm{R}$ Obstetrics :normal and problem pregnancies, 7 edition

6. Monga A, editor. Gynaecology by ten teachers. London: Hodder Arnold; 2006. P.89-102.

7. Ahmed S. Major Placenta Previa: Rate, Maternal and Neonatal outcomes experience at a tertiary maternity hospital, Sohag, Egypt: a prospective study. JCDR. 2015

8. Mathuriya G, Lokhande P. Comparative study of obstetric outcome between scarred and unscarred uterus in placenta previa cases. Indian Journal of Clinical Practice. 2013;24(6).

9. Saima gul bashir , Samiea Parveen, Samina Mumtaz 424 P J M H S Vol. 11, no. 1, Jan - Mar 2017

10. Reddy R, Latha C. Placenta previa: an analysis of 4 year experience. J Obstet Gynecol India. 1999; 53-6. 